[Bull. Agr. Chem. Soc. Japan, Vol. 22, No. 1, p. 21 23, 1958]

\title{
Chlorogenic Acid in the Tobacco Leaf during Flue-curing
}

\author{
By Masatoshi Nagasawa \\ Tobacco Research Department, Central Research Institute, Japan Monopoly Corporation
}

Received September 11, 1957

\begin{abstract}
Chlorogenic acid in the tobacco leaf during flue-curing increases to about nine times as much as that of its content in the fresh leaf. This is shown as follows: fresh leaf, 0.34 ; warming stage, 0.71 ; streching stage, 0.68 ; yellowing stage, 1.61 ; fixing stage, 2.05 ; killing stage, 3.01 ; cured leaf, $3.06 \%$. From above it is clear that chlorogenic acid in the tobacco leaf is formed in considerably great quantities during flue-curing.
\end{abstract}

Although polyphenols, mainly chlorogenic acid, in the tabacco leaf during flue-curing were discussed in detail by Frankenburg1), little attention has been paid to the accurate content of chlorogenic acid during flue-curing. On the other hand, Porcsalmy2) has found that tannin (polyphenols) in Hungarian types of tobacco leaves increases during normal air-curing and flue-curing, using the Löwenthal method to the determination of tannin. However, chlorogenic acid during flue-curing has not been determined till the present. In green or cured leaf, chlorogenic acid has been determined 3,4,5). In this paper, after attempts were made, a paper chromatographic method similar to that described by Dawson and Wadas) was adopted for the determination of chlorogenic acid during flue-curing. However, the chromatography, using the same filter paper and solvent, was almost impossible to give the same $R_{F}$ values as those obtained by Dawson and Wada. This seemed to be due to the difference of the moisture of filter paper caused by humidity in the air, therefore,

1) W.G. Frankenburg, Advances i; Enzymology, 6, 309-387 (1946).

2) I. Porcsalmy, Rev. intern. tabacs, 28, 223-5 (1953); C.A. 48, 6656b.

3) F.B. Wilkinson, M. Phillips, and A.M. Bacot, J. Asso. Off. Agr. Chem., 1004-1012 (1954).

4) M. Shiroya, T. Shiroya, and S. Hattori, Physiol, Plant., 8, 594-605 (1955).

5) R.F. Dawson and E. Wada, Tobacro Sci. pub. in Tobacco, 144, No. 11. 18-21 (1957). both the solvent and filter paper were exchanged with others.

\section{EXPERIMENTAL}

Plant Material : The adult leaves of Bright yellow (1957 crop) were supplied and flue-cured by the courtesy of the Utsunomiya Tobacco Experiment Station of the Japan Monopoly Corporation. The fourth and fifth leaves located from the top were primed and collected. The collected leaves were hung in a vertical position alternatively on straw-rope for flue-curing. The temperature and humidity during flue-curing are shown in Fig. 1. The times of sampling for investiga-

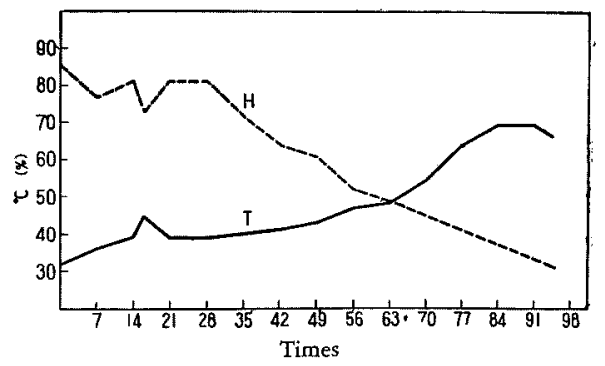

FIG. 1. Flue-curing Process.

$\mathrm{H}$ : Percent relative humidity inside the barn

$\mathrm{T}$ : Temperature inside the barn

tion are shown in Table I. The leaves used for investigation were dried in a forced-draft hot-air oven at $70^{\circ} \mathrm{C}$ for one hour and ground by a mortar and stored.

Preparation of Extract : By a method similar to that described by Dawson and Wada, $10 \mathrm{~g}$ of dried powder was refluxed with $100 \mathrm{ml}$ of 60 per cent methanol for thirty minutes on a boiling-water bath. 
TABLE I

Times AND Temperatures of SAMPling AND Contents of ChloRogenic Acid

\begin{tabular}{rlccc} 
& Hrs. & Temp. & \multicolumn{2}{c}{ Chlorogenic acid } \\
I. Fresh leaf & & 32.0 & 0.34 & 100 \\
II. Warming stage & 12 & 36.0 & 0.71 & 208 \\
III. Streching stage & 19 & 39.0 & 0.68 & 200 \\
IV. Yellowing stage & 44 & 41.0 & 1.61 & 473 \\
V. Fixing stage & 61 & 47.5 & 2.05 & 602 \\
VI. Killing stage & 74 & 57.0 & 3.01 & 885 \\
VII. Cured leaf & 95 & - & 3.06 & 900 \\
& a: calculated to original dry-weight basis. \\
The calcium content in the leaf served as the basis for making corrections.
\end{tabular}

The extract was filtered and the residue was washed with the same solvent. The combined filtrate and washings were concentrated under reduced pressure, and transferred to a $50-\mathrm{ml}$ volumetric flask and then made up to volume with water.

Quantitative Assay: Fifty microliters of the extract were applied to Töyō No. 51 filter paper sheets $(60 \times 60 \mathrm{~cm})$ and separated on the sheets with $n$-butanolbutylacetate-acetic acid-water $(2: 2: 1: 1)$ as the solvent by the descending method. After about six hours the strip was removed and allowed to dry in the air for one hour. Under these conditions, $R_{F}$ values of chlorogenic acid showed 0.65-0.68. Depside B and C, described by Dawson and Wada, should give the same $R_{F}$ values as chlorogenic acid obtained in this method. Consequently, the content of chlorogenic acid otained in this study, might have contained depside $\mathrm{B}$ and $\mathrm{C}$. The strips cut out were eluted with water and the eluates were transferred to $10-\mathrm{ml}$ volumetric flasks. Optical density measurements were made with a Beckman DU spectrophotometer at $324 \mathrm{~m} \mu$ using the eluates from blank strips of the same filter paper for zeroing the instrument. The recovery of chlorogenic acid was $69 \pm 2 \%$. The results obtained are shown in Table I.

\section{RESULTS AND DISCUSSION}

Roberts $^{6}$ ) described that if the leaf is still moist when the critical temperature is reached at which the semi-permeability of the protoplasmic membranes breaks down (about $55^{\circ} \mathrm{C}$ ), polyphenols diffuse into the cytoplasm where they are oxidized to form brownish red pigments. According to his theory, the enzyme causing the oxidation of phenols and polyphenols is contained in the cytoplasm in

6) E.A.H. Roberts, Biocbem. J., 35, 1289-1297 (1941). the cells of the leaf, whereas the phenolie compounds are in the extracellular medium7). In flue-cured leaf the polyphenols are "frozen" in the leaf without further changes owing to the rapid removal of most of the moisture from the leaf and to the inactivation of the oxidative enzymes by the high final temperatures of the flue-curing process8). Therefore, it is assumed that the content of chlorogenic acid of fresh leaf should be rather more than that of flue-cured leaf. However, it is proved from the results of this investigation that the chlorogenic acid increases during flue-curing to about nine times as much as that content in the fresh leaf, especially more increases are observed in yellowing, fixing and killing stages, as shown in Table I. It is clear that the chlorogenic acid is formed in considerably great quantities during flue-curing, as Porcsalmy described about polyphenols in tobacco leaves during flue-curing2).

The mechanism by which chlorogenic acid is formed during flue-curing is assumed to be as follows:

In the tobacco leaf during flue-curing, the enzymes, such as oxidase and peroxidase, are strongly activated9,10) and the oxygen uptake increases ${ }^{6,10)}$. As a result, oxidative respiration in the tissues comes to a high level. For

7) E.A.H. Roberts, Advances in Enzymology, 2, 113 (1942).

8) W.G. Frankenburg, Advances in Enzymology, 10, 348 (1950).

9) T. Nakai and Y. Inaba, J. Agr. Cbem. So.. Japan, 24, 105-110 (1951).

10) K. Ishidoya and S. Matsuyama, Bull. Okayama Tobacco Exp. Sta. Japan Monop. Corp., 15, 68-75 (1957). 
the suppression of the Embden-Meyerhof- that is, a normal intermediate in the direct Parnas pathway by oxygen, known as the oxidative pathway, as that in the biosynthesis Pasteur effect, the direct oxidative pathway may take place exceedingly on the glycolytic process, as described by Engelhardt11). In consequence, chlorogenic acid may derive its benzene ring from a series of precursors through sedoheptulose-1,7-diphosphate ${ }^{12,13)}$,

11) W.A. Engelhardt and N.E. Sakov, Biocbimiya, 8, 9 (1943); C.A. 37, 66808 .

12) I. Uritani and G. Akazawa, Kagaku, 25, 614-620 (1955).

13) K. Tamari and J. Kaji, J. Agr. Chen. Soc. Japan, 31. 538-544 (1957). of the benzene ring of tyrosine, phenylalanine and tryptophane as described by Davis ${ }^{14)}$.

Acknowledgement. The author wishes to thank to Miss. Taeko Itaishi for her assistance in carrying out the determination of chlorogenic acid, and to Mr. M. Ihida, Mr. T. Kisaki, and Mr. K. Saito for their cooperations for sampling of the leaves.

14) B.D. Davis, Advanses in Enzymology, 16, 287-295 (1955). 